\title{
Numerical study of forced convection heat transfer in an oscillating lid driven cavity with heated top wall
}

\author{
Jagadeesh V. Indukuri, Ranjith Maniyeri*
}

Department of Mechanical Engineering, National Institute of Technology Karnataka (NITK), Surathkal, Mangalore-575025, Karnataka, India

Corresponding Author Email: mranji1@nitk.edu.in

https://doi.org/10.18280/ijht.360429

Received: 12 September 2017

Accepted: 9 October 2018

\section{Keywords:}

finite volume method, SIMPLE algorithm, oscillating lid-driven cavity, Reynolds number, Prandtl number

\begin{abstract}
The present work is aimed to study the fluid flow and heat transfer behaviour in an oscillating lid-driven cavity using finite volume method by developing a two-dimensional computational model. Firstly, the developed computational model is validated by comparing our numerical results with that of the other researcher's results for the case of wall moving with finite motion. Next, the simulations are conducted for oscillating cavity problem with top wall oscillation for Reynolds number $(\operatorname{Re}=500)$ and frequency $\left(\omega=\frac{2 \pi}{6}\right)$. Later, the simulations are carried out for cases of oscillating parallel wall (upper and lower walls oscillating with sync) and oscillating anti-parallel wall (upper and lower walls oscillating with reverse sync) with the same optimum frequency and fixed Reynolds number $(\operatorname{Re}=500)$. Secondly, the same optimum frequency is used to study the heat transfer characteristics in an oscillating lid-driven square cavity with heated top wall and lower cold wall for various Reynolds numbers $(\operatorname{Re}=100-1000)$ and Prandtl numbers $(\operatorname{Pr}=0.2$ to 1.0$)$. From this study, it is found that for high Prandtl number case $(\mathrm{Pr}=1.0)$ the flow of high temperature isotherms inside the cavity is more when compared with low Prandtl number cases due to increase in molecular diffusion of momentum.
\end{abstract}

\section{INTRODUCTION}

Cavity flows have many endless industrial applications such as cooling of electronic devices, processing of materials, crystal growth, glass production, metal casting, solar collectors, heat exchangers etc. The study of cavity flow problems like lid driven cavity models helps us to understand the several numerical methods in the field of Computational fluid dynamics. In the present work, the developed numerical model is used to study the fluid motion and heat transfer features inside an oscillating lid driven square cavity using finite volume method with staggered grid arrangement. In the area of Computational fluid dynamics (CFD) recently finite volume based numerical solvers has become popular because of their strong conservativeness [1].

There are many experiments conducted to study the special effects of end walls on the dimension of the secondary vortex and also for different spanwise aspect ratios by varying Reynolds numbers (Re) from 1000 to 10,000 [2-5]. Several computational studies have been reported for the cases of cavity flows for various configurations of wall motions using different numerical methods like finite element method, finite difference method, lattice Boltzmann method, stream vorticity approaches etc. [6-9]. There is also research reported on cavity flows for various aspect ratios and also about the flow field changes from a stable balance state to a stable unbalanced state [10-12]. There are several studies reported on various heating conditions of the lid which are moving with finite velocity for various flow and heat transfer parameters like Reynolds, Grashof and Prandtl numbers [1316]. Based on the literature survey it is found that the study of fluid flow and heat transfer parameters in an oscillating lid driven cavity using finite volume staggered grid system is given less attention. Iwatsu et al. [17] have carried out numerical experiments in a cubic cavity with an oscillating lid. They have investigated for oscillating top wall motion with Re up to 2000 and frequency less than or equal to 10 . They reported the three-dimensional flow behaviour structures in a cubic cavity, and they concluded that for the cases of low Re the overall characteristics of main threedimensional flow can be approximated by two-dimensional flow predictions. Later, Sriram et al. [18] prepared an experimental setup to investigate the flow structures behaviour in a cavity which is driven periodically. In their studies, they examined the flow in an intermittently driven cavity using Particle Image Velocimetry (PIV) and the experimental results are compared with CFD software. Coming to computational investigations, Mendu et al. [19] has carried out the numerical investigations on a lid driven cavity problem with an oscillating lid using lattice Boltzmann method. They have done several numerical computations for Reynolds number 100, 400, 1000 by varying lid frequency. They made a remarkable conclusion that only a thin zone of the fluid nearby the lid is kept in disturbance with a combination of high frequency and high Reynolds number. Recently, $\mathrm{Hu}$ et al. [20] carried out numerical investigations in cavity moved by an external oscillating lid using smoothed particle hydrodynamics method. Firstly, they have validated for the standard cases and then, they evaluated for the case of oscillating top lid with $\mathrm{Re}=100$ and frequency $=\frac{2 \pi}{6}$. They concluded that, the fluid flow generated by the oscillating 
wall is periodic. Coming to the combined investigation of flow and heat transfer characteristics Saeidi et al. [21] have performed the numerical studies in a cavity driven by forced convection with inlet and outlet ports. They mainly investigated on both flow pattern and isothermal behaviour in a cavity for various distances between the inlets and outlet ports and also given the dimensionless wall coordinates of output port having minimum pressure drop and maximum heat transfer. Numerical investigations on heated cavity problem with forced convection heat transfer are done using large eddy simulation by Dos et al. [22]. In their analysis, they mainly developed a numerical method for estimating the incompressible laminar and turbulent flows and nonisothermal behaviour. They have developed a finite element model to simulate the forced convection behaviour inside a cavity for Reynolds number ranging from $(\mathrm{Re}=100$ to 10000$)$ and Prandtl number $(\mathrm{Pr}=1.0)$. Recently, Varma and Maniyeri [23] have done numerical simulations using finite volume method on oscillating lid driven cavity for different combinations of Reynolds number and frequencies. They have investigated mainly flow analysis for various wall configurations.

Based on the literature review it is concluded that a huge amount of research has done on lid driven cavity flow problems using various numerical techniques like finite element method, stream vorticity approaches, finite difference method and lattice Boltzmann method. The research is mostly concentrated on the lid driven cavity problems having walls moving with finite motions, also the variation in depth of the cavity and for different wall geometries. From the critical review of the literature, it is inferred that less amount of work on oscillating lid driven cavity flow problem using finite volume methods has been reported. To the best of our knowledge, it is understood that no investigations have been reported on oscillating lid driven cavity problem to study the flow and forced convection heat transfer characteristics using finite volume method. Inspired by this, we have developed a two-dimensional numerical model based on finite volume method to study the flow and heat transfer characteristics in an oscillating lid driven cavity. Numerical simulations are carried out for a range of Reynolds number and frequency. Based on the strong fluid disturbances, an optimum Reynolds number and frequency is chosen to perform simulations for flow problem having single wall, parallel wall and anti-parallel wall oscillations. Finally, simulations are carried out for the oscillating lid driven cavity with top heated lid for various Reynolds number $(\mathrm{Re}=100$ to 1000$)$ and Prandtl number $(\mathrm{Pr}=0.1$ to 1.0$)$ with the optimum frequency.

\section{MATHEMATICAL MODELLING NUMERICAL PROCEDURE}

AND

Figure 1 represents the actual domain of the dimensional lid-driven cavity with an oscillating lid having heated top wall. In this physical domain, the top wall is given oscillation using the function $\mathrm{u}^{*}=\mathrm{u}_{\mathrm{ref}}{ }^{*} \cos \left(\omega^{*} \mathrm{t}^{*}\right)$, where $\mathrm{u}_{\mathrm{ref}}{ }^{*}$ is the maximum velocity of lid called amplitude, $\omega^{*}$ is the lid frequency and $t^{*}$ is the oscillation time period. The oscillating top wall is maintained at a higher temperature which is signified as $\left(\mathrm{T}_{\mathrm{h}}{ }^{*}\right)$ and the stationary bottom wall is considered as cold wall given by $\left(\mathrm{T}_{\mathrm{c}}{ }^{*}\right)$ and the left and right side walls are considered as adiabatic. The dimensional continuity, Navier-Stokes and energy equations are taken in to account to explore the flow and isotherms behaviour inside the cavity, which are given below in the equations (1), (2) and (3).

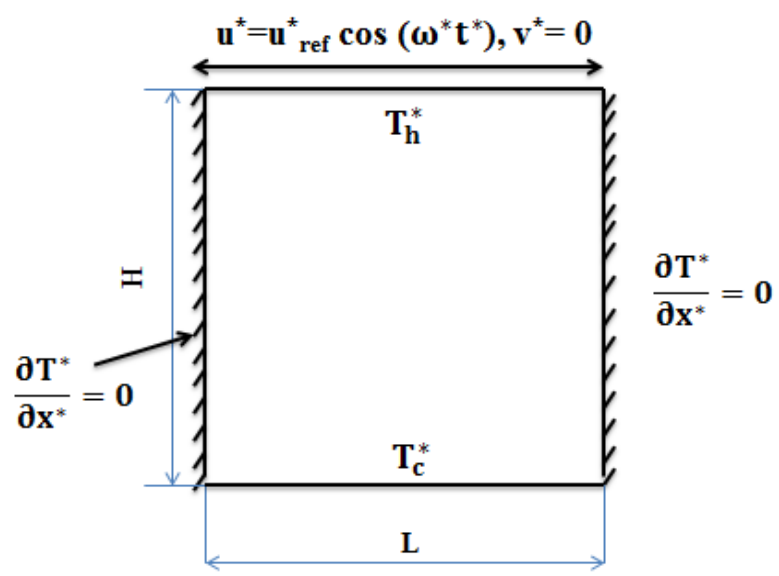

Figure 1. Schematic diagram representing the actual domain of dimensional square cavity with an oscillating lid having heated top wall

$\nabla \cdot \mathrm{u}^{*}=0$

$\rho\left(\frac{\partial \mathbf{u}^{*}}{\partial \mathrm{t}^{*}}+\mathrm{u}^{*} \cdot \nabla \mathrm{u}^{*}\right)=-\nabla \mathrm{p}^{*}+\mu \nabla^{2} \mathrm{u}^{*}$

$\rho c_{\mathrm{p}}\left(\frac{\partial \mathrm{T}^{*}}{\partial \mathrm{t}^{*}}+\left(\mathrm{u}^{*} \cdot \nabla\right) \mathrm{T}^{*}\right)=\mathrm{k} \nabla^{2} \mathrm{~T}^{*}$

The dimensional boundary conditions are

$$
\begin{array}{ll}
\mathrm{u}^{*}=\mathrm{u}^{*} \operatorname{ref} \cos \left(\omega^{*} \mathrm{t}^{*}\right), \mathrm{v}^{*}=0, \mathrm{~T}^{*}=\mathrm{T}_{\mathrm{h}}^{*} & \mathrm{y}^{*}=\mathrm{H}, 0 \leq \mathrm{x}^{*} \leq \mathrm{L} \\
\mathrm{u}^{*}=\mathrm{v}^{*}=0, \mathrm{~T}^{*}=\mathrm{T}_{\mathrm{c}}^{*} & \mathrm{y}^{*}=0,0 \leq \mathrm{x}^{*} \leq \mathrm{L} \\
\mathrm{u}^{*}=\mathrm{v}^{*}=0, \frac{\partial \mathrm{T}^{*}}{\partial \mathrm{x}^{*}}=0 & \mathrm{x}^{*}=0,0 \leq \mathrm{y}^{*} \leq \mathrm{H} \\
\mathrm{u}^{*}=\mathrm{v}^{*}=0, \frac{\partial \mathrm{T}^{*}}{\partial \mathrm{x}^{*}}=0 & \mathrm{x}^{*}=\mathrm{L}, 0 \leq \mathrm{y}^{*} \leq \mathrm{H}
\end{array}
$$

Here, $\mathbf{u}^{*}, \rho, \mathrm{p}^{*}, \mu, \mathrm{T}^{*}, \mathrm{k}, \mathrm{c}_{\mathrm{p}}$ are defined as fluid velocity, fluid density, fluid pressure, dynamic viscosity, temperature, thermal conductivity and specific heat of the incompressible fluid. The continuity, Navier-Stokes and energy equations are non-dimensionalised using the standard reference length (L), standard reference velocity $\left(\mathrm{u}^{*}\right.$ ref $)$ and for temperature two extreme values $\left(\mathrm{T}_{\mathrm{h}}{ }^{*}\right.$ and $\left.\mathrm{T}_{\mathrm{c}}{ }^{*}\right)$ are used which are shown below

$$
\begin{aligned}
& \mathrm{U}=\frac{\mathrm{u}^{*}}{\mathrm{u}_{\mathrm{ref}}^{*}}, \mathrm{~V}=\frac{\mathrm{v}^{*}}{\mathrm{u}_{\mathrm{ref}}^{*}}, \mathrm{X}=\frac{\mathrm{x}^{*}}{\mathrm{~L}}, \mathrm{Y}=\frac{\mathrm{y}^{*}}{\mathrm{~L}}, \omega=\frac{\omega^{*} \mathrm{~L}}{\mathrm{u}_{\mathrm{ref}}^{*}}, \mathrm{P}=\frac{\mathrm{p}^{*}}{\rho \mathrm{u}_{\mathrm{ref}}^{*}}, \mathrm{t}= \\
& \frac{\mathrm{t}^{*} \mathrm{uref}_{\mathrm{ref}}^{*}}{\mathrm{~L}}, \mathrm{~T}=\left(\frac{\mathrm{T}^{*}-\mathrm{T}_{\mathrm{c}}^{*}}{\mathrm{~T}_{\mathrm{h}}^{*}-\mathrm{T}_{\mathrm{c}}^{*}}\right)
\end{aligned}
$$

Figure 2 represents the physical domain of the nondimensional oscillating lid-driven cavity with the heated top wall. In this physical domain, the top wall is given an oscillation using the non-dimensional function $\mathrm{U}=\cos (\omega \mathrm{t})$ where $U$ is termed as non-dimensional velocity of lid, $\omega$ is the non-dimensional frequency of lid motion and ' $t$ " is the non- dimensional time period of oscillation. The oscillating 
top wall is maintained at high temperature given by $(\mathrm{T}=1.0)$ and bottom wall is considered to be cold wall represented as $(\mathrm{T}=0)$ and remaining left and right side walls are treated as adiabatic walls. The non-dimensionalised governing equations obtained are shown below in the equations (4), (5) and (6).

$\nabla \cdot \mathrm{U}=0$

$\left(\frac{\partial \mathrm{U}}{\partial \mathrm{t}}+\mathrm{U} \cdot \nabla \mathrm{U}\right)=-\nabla \mathrm{P}+\frac{1}{\mathrm{Re}} \nabla^{2} \mathrm{U}$

$\left(\frac{\partial \mathrm{T}}{\partial \mathrm{t}}+(\mathrm{U} . \nabla) \mathrm{T}\right)=\frac{1}{\operatorname{RePr}} \nabla^{2} \mathrm{~T}$

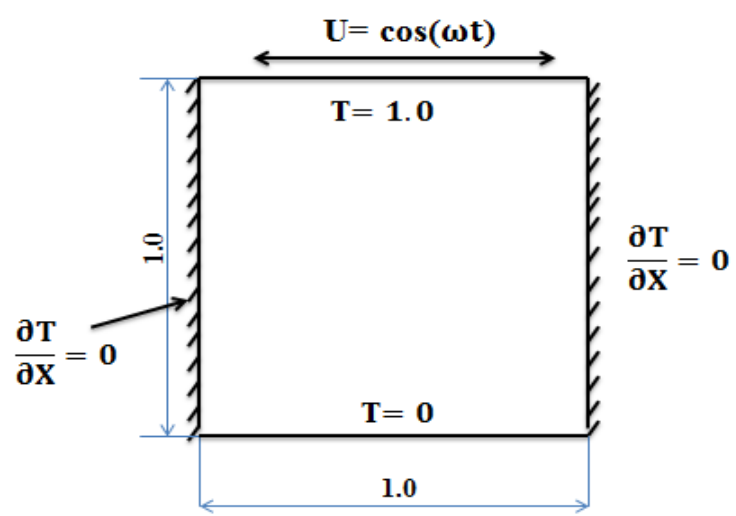

Figure 2. Schematic diagram representing the nondimensional square cavity with an oscillating lid having heated top wall

The non-dimensional boundary conditions are given below for oscillating case

$\mathrm{U}=\cos (\omega \mathrm{t}), \mathrm{V}=0, \mathrm{~T}=1.0$

$\mathrm{Y}=1.0$,

$0 \leq \mathrm{X} \leq 1.0$

$\mathrm{U}=\mathrm{V}=0, \mathrm{~T}=0$

$\mathrm{Y}=0$,

$0 \leq \mathrm{X} \leq 1.0$

$\mathrm{U}=\mathrm{V}=0, \frac{\partial \mathrm{T}}{\partial \mathrm{X}}=0$

$\mathrm{X}=0$,

$0 \leq \mathrm{Y} \leq 1.0$

$\mathrm{U}=\mathrm{V}=0, \frac{\partial \mathrm{T}}{\partial \mathrm{X}}=0$

$\mathrm{X}=1.0$,

$0 \leq \mathrm{Y} \leq 1.0$

Here, Re is Reynolds number given by $\operatorname{Re}=\frac{\rho \mathrm{u}_{\mathrm{ref}}^{*} \mathrm{~L}}{\mu}$ and $\operatorname{Pr}$ is Prandtl number given by $\operatorname{Pr}=\frac{v}{\alpha}$, where $v$ is kinematic viscosity and $\alpha$ is thermal diffusivity.

The average dimensionless Nusselt number for the cavity is found along the top wall which is given by the equation (7)

$\overline{\mathrm{Nu}}=-\int_{0}^{1} \frac{\partial \mathrm{T}}{\partial \mathrm{Y}} \mathrm{dX}$

By averaging the average Nusselt number for a single oscillating solution we obtain the time-averaged Nusselt number expressed by the following relation given in equation (8).
$\overline{\overline{\mathrm{Nu}}}=\frac{\int_{0}^{\mathrm{t}} \overline{\mathrm{Nu}} \mathrm{dt}}{\mathrm{T}_{\mathrm{n}}}$

where $T_{n}$ is total time taken for single oscillating solution.

SIMPLE (Semi-Implicit Method for Pressure-Linked Equations) algorithm [24] is employed to solve the continuity, momentum and energy equations. The convective terms in the Navier-Stokes equations and advection terms in energy equation are discretized using first-order UPWIND scheme. A finite volume method with staggered arrangement is employed. The resulting algebraic equations are solved using tridiagonal matrix algorithm (TDMA). The normal residue method is taken as convergence criteria for each flow variable, the iterations are carried out until the periodic solution is obtained.

A convergence criterion is taken in to account for solving the momentum and energy equations in the case of steadystate problem which is shown in equation (9). Since our problem deals with unsteady state case, we have confirmed that the solution is oscillatory after certain time periods and then the results are taken at certain time steps.

$\left(u_{i, j}-u_{i-1, j}\right) \Delta y+\left(v_{i, j}-v_{i, j-1}\right) \Delta x \leq 10^{-7}$

\section{RESULTS AND DISCUSSIONS}

\subsection{Grid independence study}

The grid independence test is performed for lid driven square cavity having top wall motion with Reynolds number $(\mathrm{Re}=1000)$ and the remaining walls are kept stationary. Mainly, the grid independent study is made for three different uniform grid sizes of $65 \times 65,129 \times 129$ and $251 \times 251$. The $x$ component of centreline velocity is taken into consideration for different grid sizes. Figure 3 represents the variation of geometric centre velocity for three different grid sizes. From figure 3 it is perceived that the solution accuracy is nearly the same for the case of $129 \times 129$ and $251 \times 251$ with a variation of only $5 \%$. Since, it is observed that the grid size $251 \times 251$, taking large computational time to calculate the same results, we selected $129 \times 129$ as the optimum grid size for further simulations.

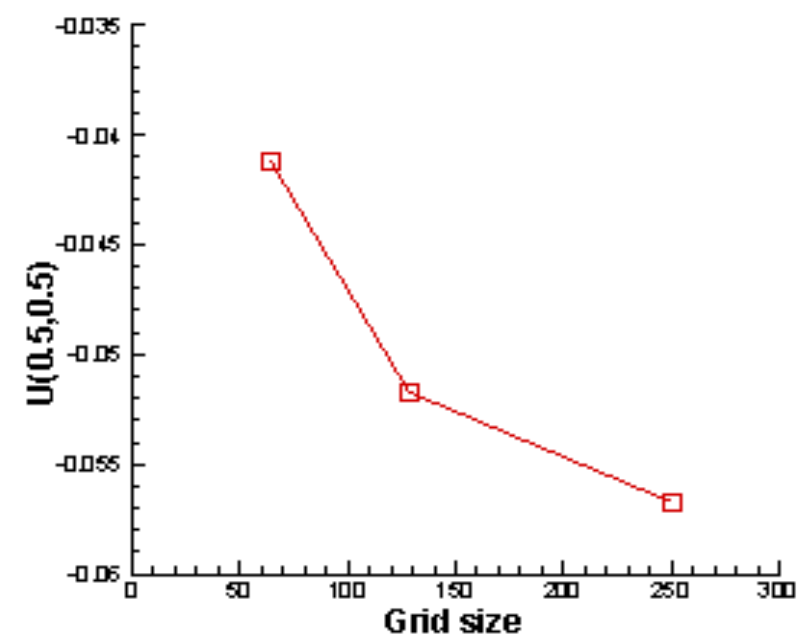

Figure 3. Schematic diagram representing the centreline velocity for various grid sizes 


\subsection{Validation of the developed model}

In the present work, a two-dimensional numerical model is developed using finite volume method. For validation purpose, the numerical simulation is carried out with a model having cavity size of $1 \times 1$, mesh size of $129 \times 129$ and time step of 0.01 . Here, the upper wall of the square cavity is modelled with finite wall motion and the other walls are kept as inactive. Then, the simulated results are compared with that of Ghia et al. [6] results. Figure 4 illustrates the results plotted between centreline $\mathrm{u}$ velocity variation with $\mathrm{y}$-axis and centreline $\mathrm{v}$ velocity variation with respect to $\mathrm{x}$-axis for $\mathrm{Re}=1000$. A good agreement is obtained with that of Ghia et al. [6] proving the validity of the developed model.

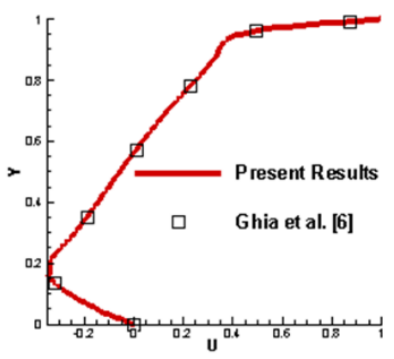

(a)

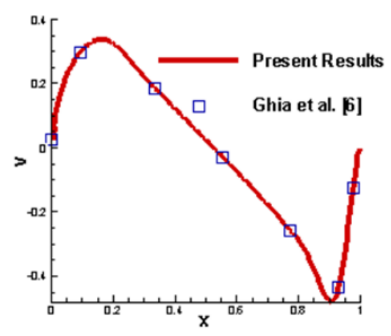

(b)
Figure 4. Validation of current numerical model for $\mathrm{Re}=1000$ (a) mid-line $\mathrm{x}$ component velocity deviation along $\mathrm{y}$-axis (b) mid-line v velocity deviation along $\mathrm{x}$-axis

\subsubsection{Oscillating upper wall}

After validating the developed model with finite wall motion, then it is used to simulate the fluid behaviour happening inside the cavity for oscillating wall cases (upper wall, upper and lower walls sync, and upper and lower walls reverse sync). Several numerical simulations are executed for a combination of Reynolds number $(\mathrm{Re}=100,500,1000$ and
$2000)$ and frequency of lid " $\omega "\left(\omega=\frac{\pi}{6}, \frac{2 \pi}{6}, \frac{5 \pi}{6}, \pi, \frac{4 \pi}{3}, 2 \pi\right)$. The flow field in the cavity becomes periodic with the lid motions. Every frequency has certain periodic oscillations, based on that a time period has been decided to capture vortex behaviour inside the cavity. The results are captured only after certain lid oscillations ensuring that, the solution is periodic even though the results are captured above that time period limit.

Figure 5(a) displays the mid-line $\mathrm{U}$ and $\mathrm{V}$ velocity deviation along $\mathrm{Y}$ and $\mathrm{X}$ axis, for the case of $\mathrm{Re}=100$ and lid frequency $\omega=\frac{2 \pi}{6}$ (optimum frequency selected for this work based on simulations results of different frequency values) which are agreeing with that of Mendu et al. [19] shown in figure 5(b). From figure 5(a) it is analysed that, the top fluid particles close to the lid also practice the same path because of no-slip boundary condition, whereas the velocity remains still at the lower wall. Figure 5(a) shows the mid-line $u$ velocity variation for first half time period at an instant time period $(\mathrm{t}=1.2)$. It is observed that mid-line fluid particles behaviour is unusual when related to that of mid-line $u$ velocity variation for constant lid motion case shown in figure 4 . It is concluded that, the velocity variation of fluid particles from upper to lower part shows more intricate action than the case of constant wall motion. This phenomenon is happening because the fluid velocity is dependent on the rapid motion of lid and also the fluid velocities at the previous time instant. Since the lid is driven by some oscillations, the centre-line velocity behaviour is more complex when compared to the case of finite wall motion.

Several numerical simulations are done by changing the frequency and Reynolds number, from these simulations it is concluded that for an optimum frequency $\omega=\frac{2 \pi}{6}$ and Reynolds number $(\mathrm{Re}=1000)$ fluid mixing is strong. Since those results are reported in our previous work [23], in this paper, results are presented for the case of $\mathrm{Re}=500$ and optimum frequency $\left(\omega=\frac{2 \pi}{6}\right)$. (a)

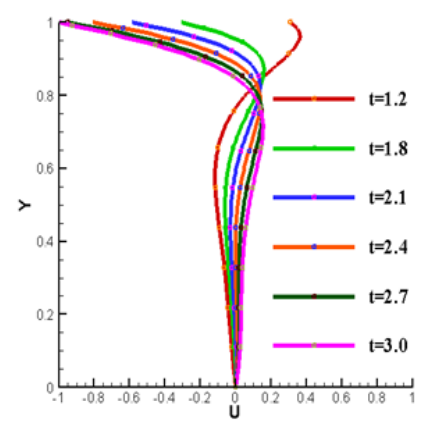

(b)

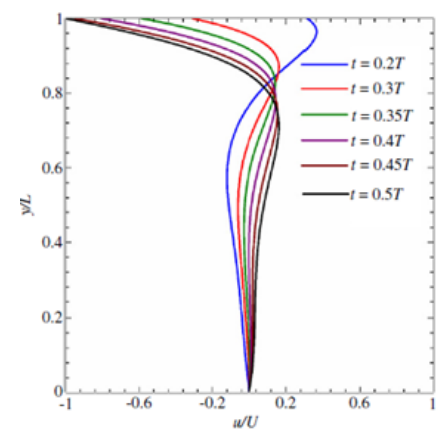

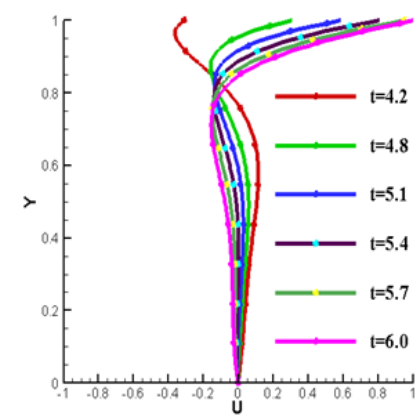

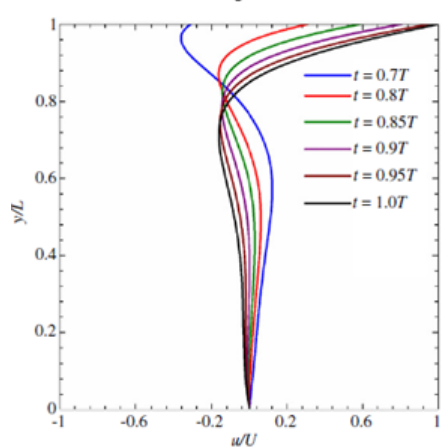

Figure 5. Mid-line $U$ and V velocity deviation for the oscillating upper wall at $\mathrm{Re}=100$ and $\omega=2 \pi / 6$ with first half of time period $(t=0$ to 3.0) and second half time period ( $t=3.0$ to 6.0). (a) Present results (b) Mendu et al. [19] results 
a.

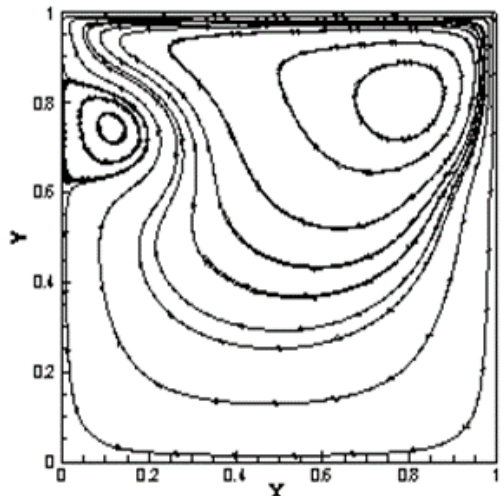

b.
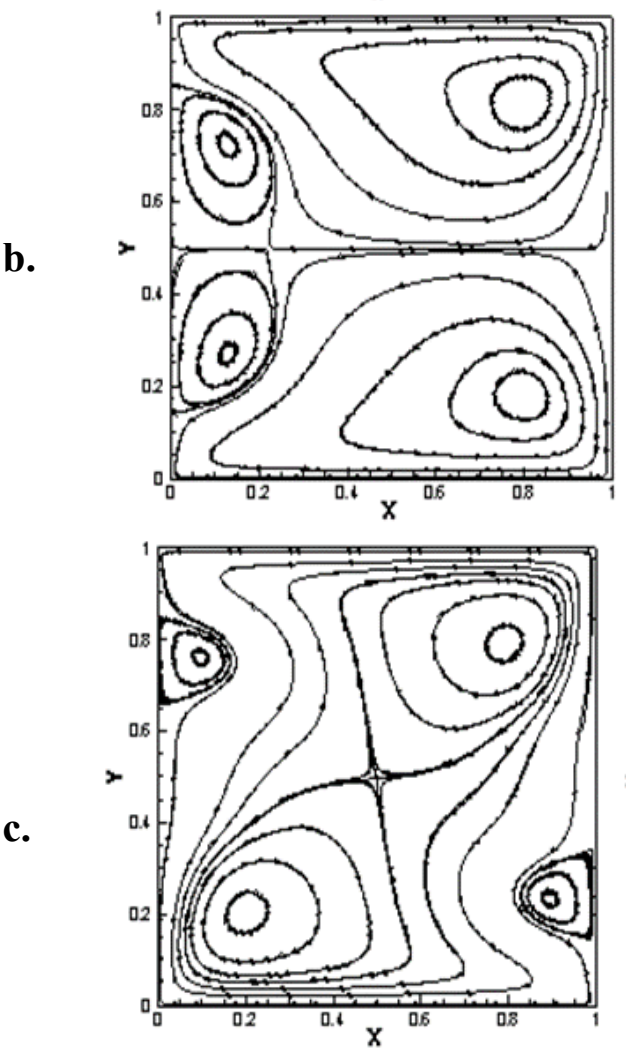

$\mathrm{t}=1.2, \mathrm{U}=0.30901$
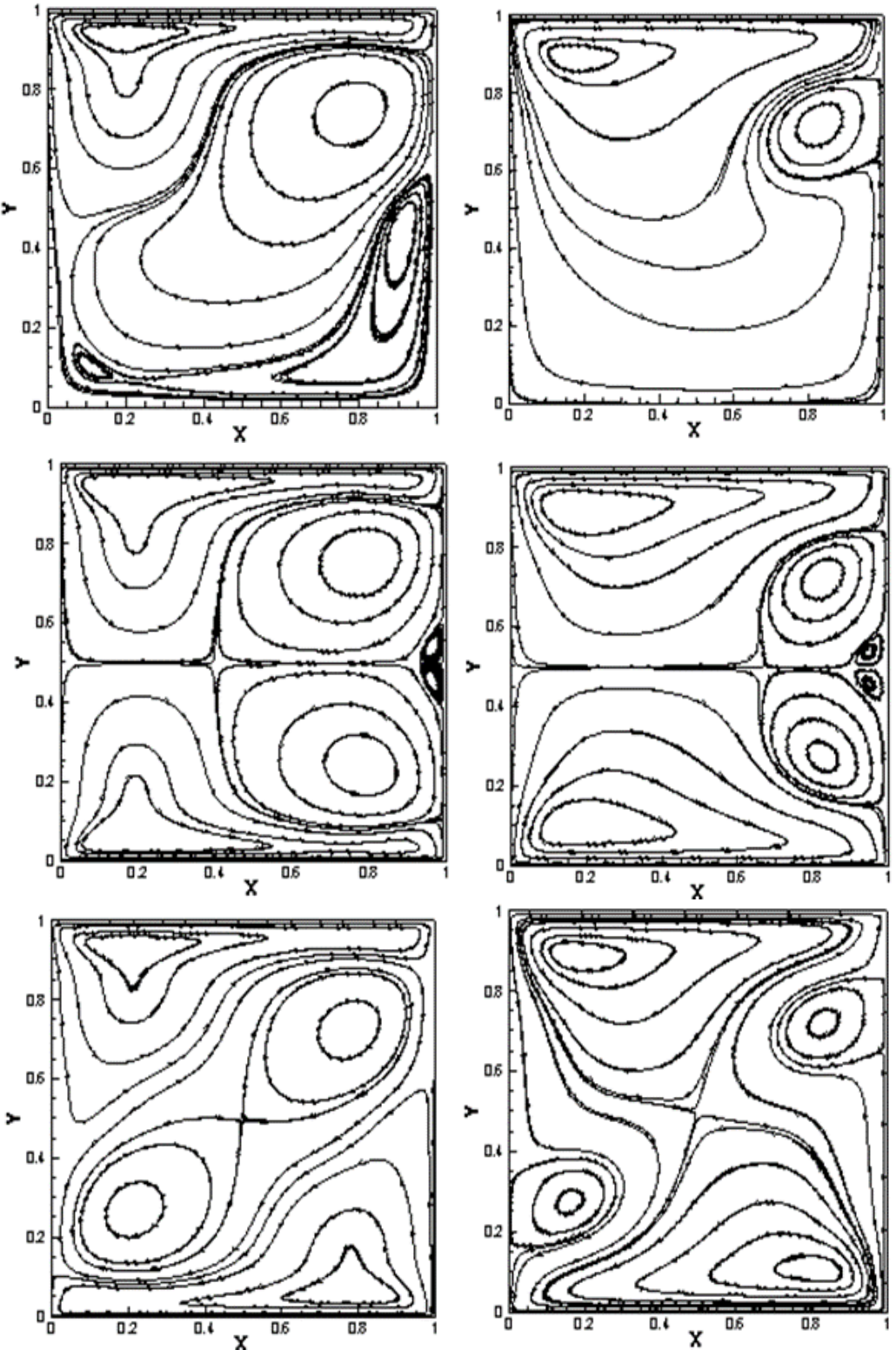

$\mathrm{t}=3.0, \mathrm{U}=-1.0$

Figure 6. Streamline patterns at several time intervals with fixed Reynolds number $(\mathrm{Re}=500)$ and optimum frequency $\omega=2 \pi / 6$ for (a) Oscillating upper wall (b) Oscillating Parallel wall with sync (c) Oscillating anti-parallel wall with reverse sync

Figure 6(a) displays the streamline arrangements for oscillating upper wall at $\mathrm{Re}=500$ and frequency $\omega=\frac{2 \pi}{6}$. From fig 6(a) it is inferred that at time $t=1.2$ the foremost part of the cavity is occupied by the primary eddy and less portion is packed by the secondary eddy at the top left corner. Similarly, as the time $(\mathrm{t}=2.1)$ progresses the lid changes its course of path $(U=-0.58779)$ in the negative direction then the secondary vortices near the top left corner formed at the previous time step $(\mathrm{t}=1.2)$ tries to enlarge its size by interacting with counter-rotating vortex.

If we observe clearly at time $(\mathrm{t}=2.1)$ four counter-rotating eddies are present inside the cavity indicating that more streamline interactions are happening. Finally, as the time progresses in the first half of time period $(t=3.0)$, most of the space in the cavity is occupied by a counter-rotating eddy separating the primary eddy at the right topmost corner inside the cavity.

Figure 7 depicts the distribution of vorticity contours inside the cavity showing the cases of oscillating upper wall, oscillating upper and lower wall sync and oscillating upper and lower wall reverse sync at $\mathrm{Re}=500$ and $\omega=\frac{2 \pi}{6}$. The dark lines indicate positive trend of vorticity and dashed lines as negative trend of vorticity. The vorticity gradients are not high in case of single-wall oscillation mainly at the bottom part of the cavity. This indirectly indicates that the momentum transfer for the case of single-wall oscillation is taking place near to the lid. 
(a)

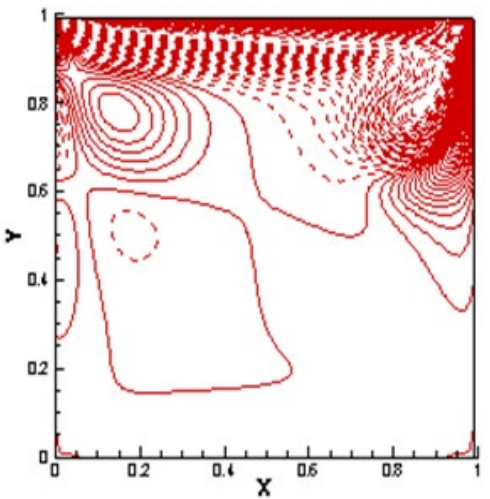

(b)

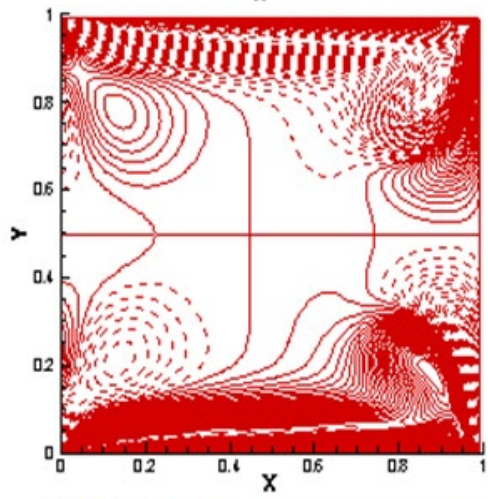

(c)

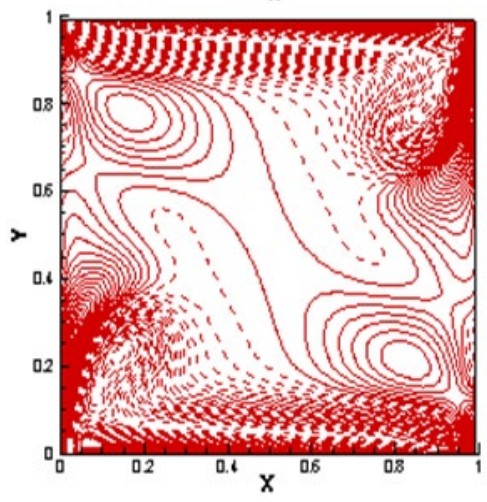

$\mathrm{t}=1.2, \mathrm{U}=0.30901$
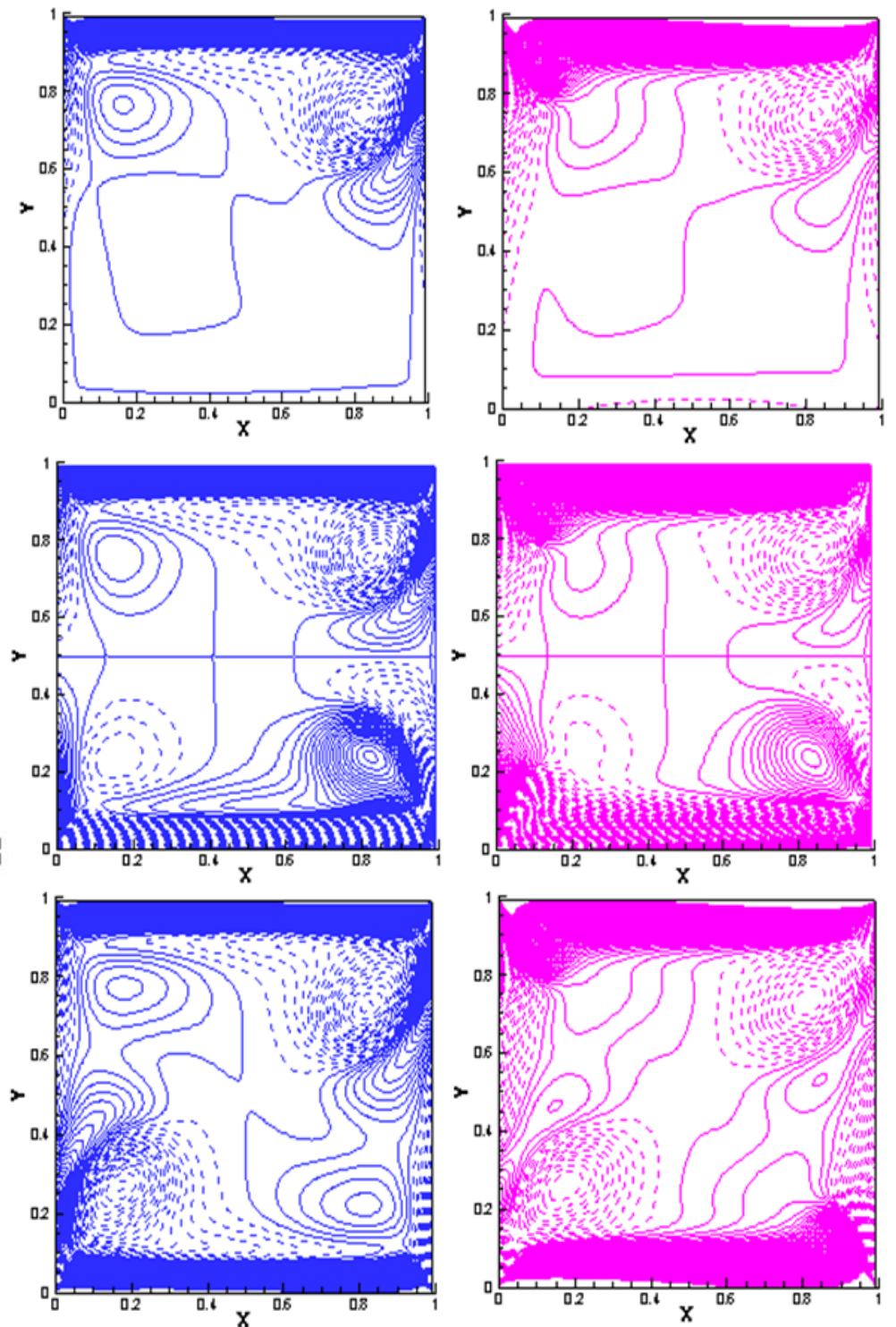

$\mathrm{t}=2.1, \mathrm{U}=-0.58779$

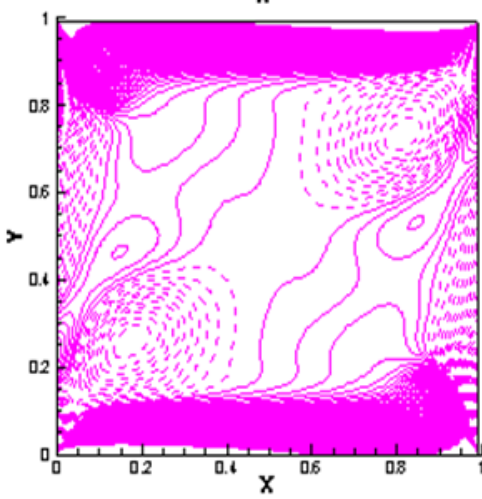

$\mathrm{t}=3.0, \mathrm{U}=-1.0$

Figure 7. Vorticity contours with optimum frequency $\omega=2 \pi / 6$ and Reynolds number ( $R e=500$ ) (a) Oscillating upper wall (b) Oscillating parallel wall sync (c) Oscillating anti-parallel wall reverse sync

\subsubsection{Parallel wall oscillation}

Next, the simulations are carried out for parallel wall motion at $\operatorname{Re}=500$ and $\omega=\frac{2 \pi}{6}$. Figure $6(\mathrm{~b})$ shows the streamline arrangements for oscillating parallel wall sync case with $\mathrm{Re}=500$ and fixed frequency $\omega=\frac{2 \pi}{6}$. It can be seen that primarily at the starting time period $(t=1.2)$, a primary eddy located at the top and bottom part of the cavity which are mirror images of each other are formed. Also mirrored secondary eddies at the left wall side is observed. As the time $(t=2.1)$ increment continues, mirrored secondary eddies beside the left wall enlarge its size by interacting with the counter-rotating vortex formed due to the changes in the path of action (negative direction) of the lid at the upper and lower part of the cavity. Coming to the end of first half period $(t=$ 3.0) most of the space inside the cavity is occupied by the mirrored counter-rotating eddies at the upper and lower part of the cavity separating the mirrored primary eddy and small secondary eddy at the right side wall of the cavity.

Figure 7(b) indicates the vorticity contours for the case of Oscillating Parallel wall sync. The vorticity gradients are high for the cases of Reynolds number $(\mathrm{Re}=500)$ when compared to single wall oscillation case at different time intervals.

\subsubsection{Anti-parallel wall oscillation}

Finally, the simulations are carried out for oscillating antiparallel wall reverse sync case with $\mathrm{Re}=500$ and fixed frequency $\omega=\frac{2 \pi}{6}$. Figure $6(\mathrm{c})$ represents the streamline arrangements of oscillating anti-parallel wall reverse sync case at $R e=500$ and $\omega=\frac{2 \pi}{6}$. It can be seen in fig 6(c) that at the prime time stage $(t=1.2)$ primary eddies containing two co-rotating eddies in it are aligned diagonally. Also, two secondary eddies near the extreme corners located at the top and bottom part of the cavity are observed. After the time $(t=2.1)$ continues to increase, then the secondary eddies present at the extreme corners of the cavity tries to enlarge its size by interacting with counter-rotating eddies formed due to the changes in the path of action (negative direction) of the lid at the upper and lower part of the cavity. Coming to the end of first half time period $(t=3.0)$, most of the space 
inside the cavity is dominated by counter-rotating eddy parting off primary eddies at the extreme corners of the cavity.

Figure 7(c) depicts the vorticity gradients for oscillating anti-parallel wall reverse sync case. From these plots, it is inferred that the vorticity gradients are high when compared to the cases of single and parallel wall oscillations which means that the momentum transfer is more in the major portion of the cavity.

\subsection{Isotherms behaviour and Nusselt number variation}

\subsubsection{Validation for heat transfer problem}

Next, after the flow analysis, the numerical model is extended for heat transfer problem. After that, the developed numerical model is used to compare our numerical results with that of Dos et al. [22] for the case of Reynolds numbers $(\mathrm{Re}=100,1000)$ and Prandtl number $(\operatorname{Pr}=1.0)$. For validation, the numerical simulation is carried out with a mesh size of $129 \times 129$ and time step of 0.01 . Validation is done for the model of cavity size $1 \times 1$ having top wall motion with constant velocity $(\mathrm{U}=1.0)$ and the remaining walls are kept stationary. Temperature boundary condition is taken as upper wall heated $(\mathrm{T}=1.0)$ and the bottom wall is considered as a cold wall $(\mathrm{T}=0.0)$, the remaining right and left walls are considered as adiabatic. Figures 8(a) and 8(b) shows the simulation results obtained using the developed model and figures $8(\mathrm{c})$ and $8(\mathrm{~d})$ shows the numerical results of Dos et al. [22]. Concluding from these figures, it is observed that the current results are favourable with the results of Dos et al. [22] and proves that our developed model is reliable.

After validation, the developed code is used to simulate the temperature contours behaviour inside the oscillating lid driven cavity with a heated top wall case (upper wall). The numerical simulations are accomplished for Reynolds numbers ( $\mathrm{Re}=100,500$ and 1000), with combinations of Prandtl numbers $(\mathrm{Pr}=0.2,0.4,0.7$ and 1.0) for a fixed lid frequency " $\omega$ " which is taken as $\frac{2 \pi}{6}$. The results are shown for the cases of $\operatorname{Pr}=0.7$ and 1.0 and $\operatorname{Re}=100,500$ and 1000 at various time intervals.

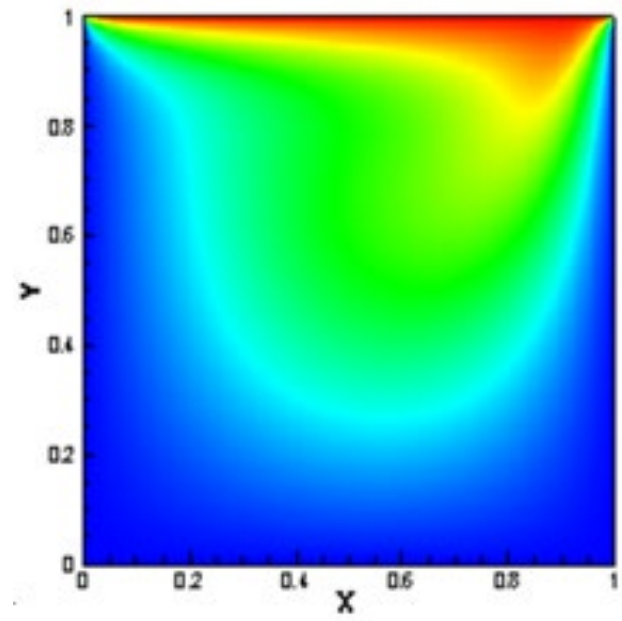

(a)

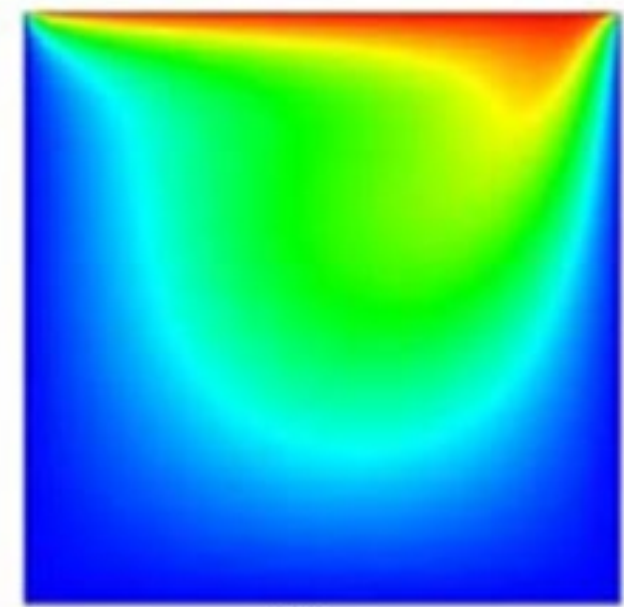

(c)

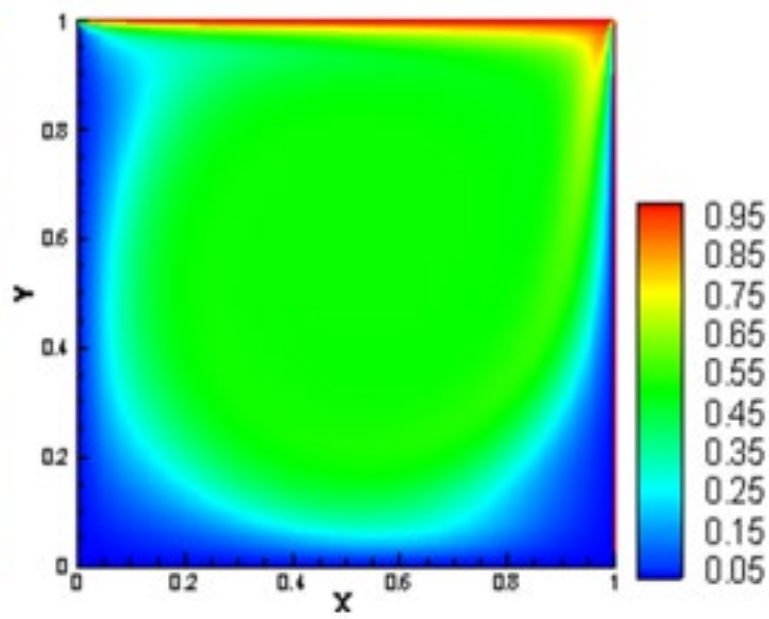

(b)

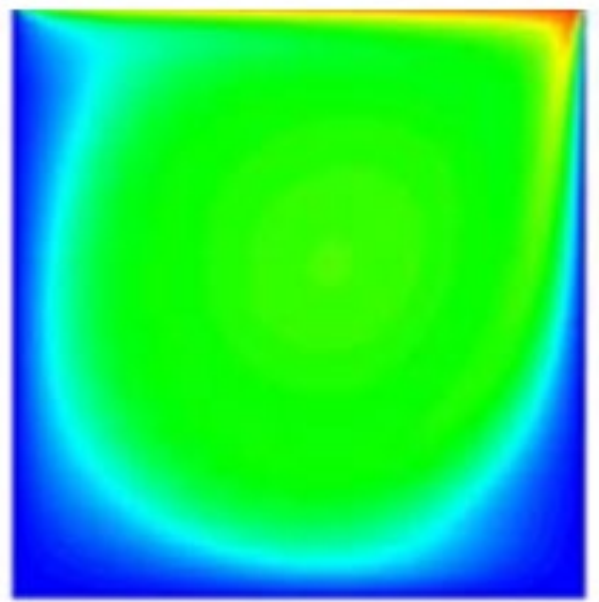

(d)

Figure 8. Schematic diagrams representing validation of present results for heated cavity with forced convection. Present results: (a) $\operatorname{Re}=100$ and $\operatorname{Pr}=1.0$ (b) $\mathrm{Re}=1000$ and $\operatorname{Pr}=1.0$; Dos et al. [22] results: (c) $\mathrm{Re}=100$ and $\operatorname{Pr}=1.0$ (d) $\mathrm{Re}=1000$ and $\operatorname{Pr}=1.0$ 

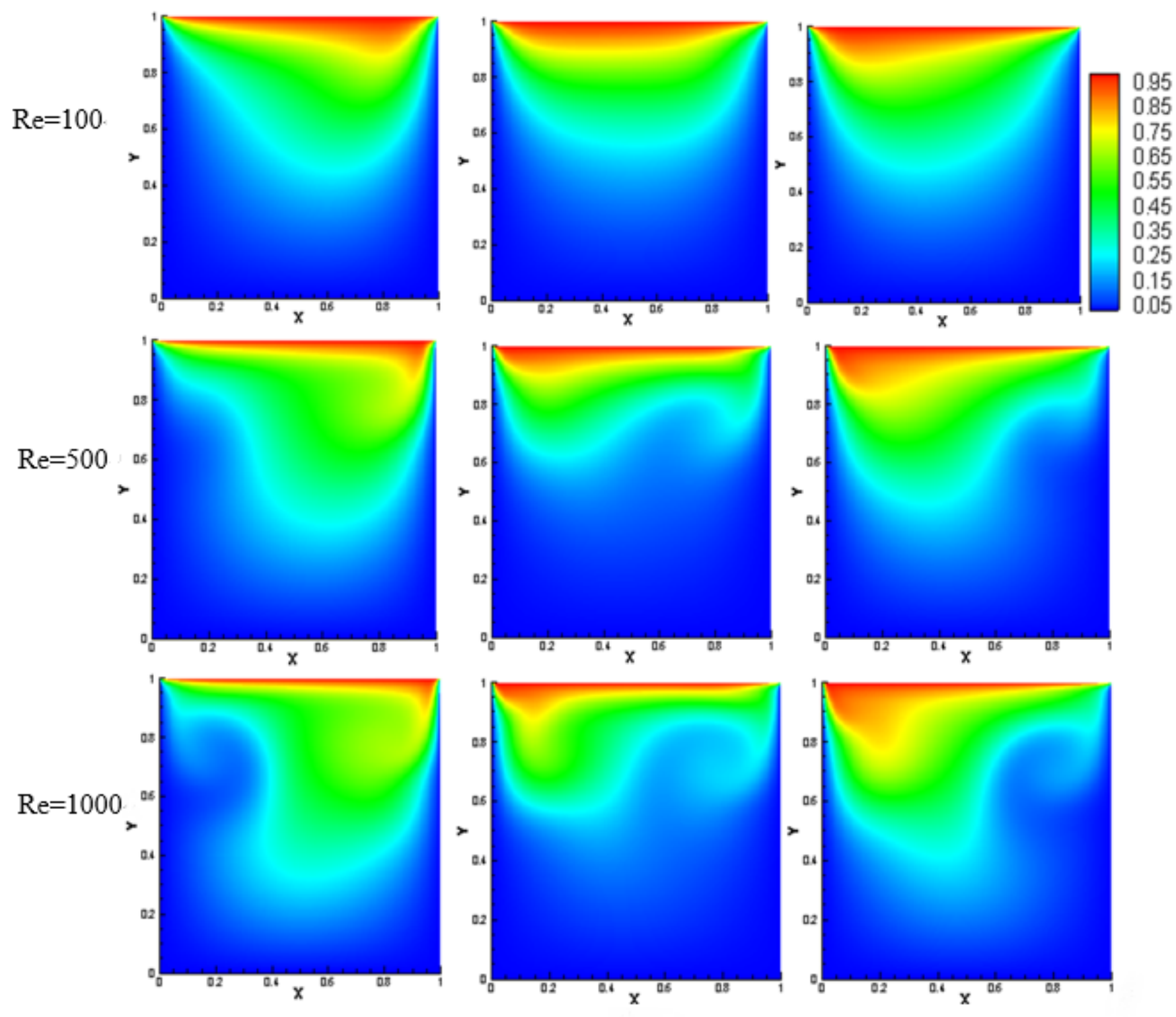

$\mathrm{t}=1.2, \mathrm{U}=0.30901$

$\mathrm{t}=2.4, \mathrm{U}=-0.80901$

$\mathrm{t}=3.0, \mathrm{U}=-1.0$

Figure 9. Schematic diagrams representing the temperature contours of oscillating lid driven cavity for the heated top wall at first half cycle with $\omega=2 \pi / 6, \operatorname{Pr}=0.7$ for three Reynolds numbers $(\operatorname{Re}=100,500,1000)$

Figure (9) shows the isotherms behaviour inside the cavity with an oscillating lid having top wall heated for the case of Prandtl number $\mathrm{Pr}=0.7$ and Reynolds number varying from $\mathrm{Re}=100$ to 1000 at $\omega=\frac{2 \pi}{6}$. From figure 9 it is observed that at Prandtl number $(\mathrm{Pr}=0.7)$ for different Reynolds numbers $(\mathrm{Re}=100,500,1000)$ the penetration of high-temperature contours inside the cavity increases mainly due to the increase in molecular diffusion of momentum inside the cavity.

Finally, at high Prandtl number $(\operatorname{Pr}=1.0)$, which is shown in figure 10 , the distribution of temperature contours is better when compared to the cases of low Prandtl number. This is due to growth in the molecular diffusion of momentum when compared to molecular diffusion of heat and also due to increase in the high shear fluid velocity.
Table 1. The time-averaged Nusselt number at the top lid for different cases of Prandtl number

\begin{tabular}{|c|c|c|c|c|}
\hline \multicolumn{5}{|c|}{ Time-averaged Nusselt number } \\
\hline & $\operatorname{Pr}=0.2$ & $\operatorname{Pr}=0.4$ & $\operatorname{Pr}=0.7$ & $\mathrm{Pr}=1.0$ \\
\hline $\mathrm{Re}=100$ & 7.66 & 7.76 & 7.96 & 8.25 \\
\hline $\mathrm{Re}=500$ & 8.08 & 8.85 & 9.86 & 10.72 \\
\hline $\mathrm{Re}=1000$ & 8.94 & 10.32 & 11.87 & 13.14 \\
\hline
\end{tabular}

Table 1 shows the calculated time-averaged Nusselt number for combinations of $(\mathrm{Re}=100,500,1000)$ and Prandtl number $(\operatorname{Pr}=0.2,0.4,0.7,1.0)$. From Table 1 , it is observed that the time-averaged Nusselt number is increasing with increase in Reynolds number (100-1000) for a fixed Prandtl number and the reason behind that is due to increase in momentum transfer to the fluid. 

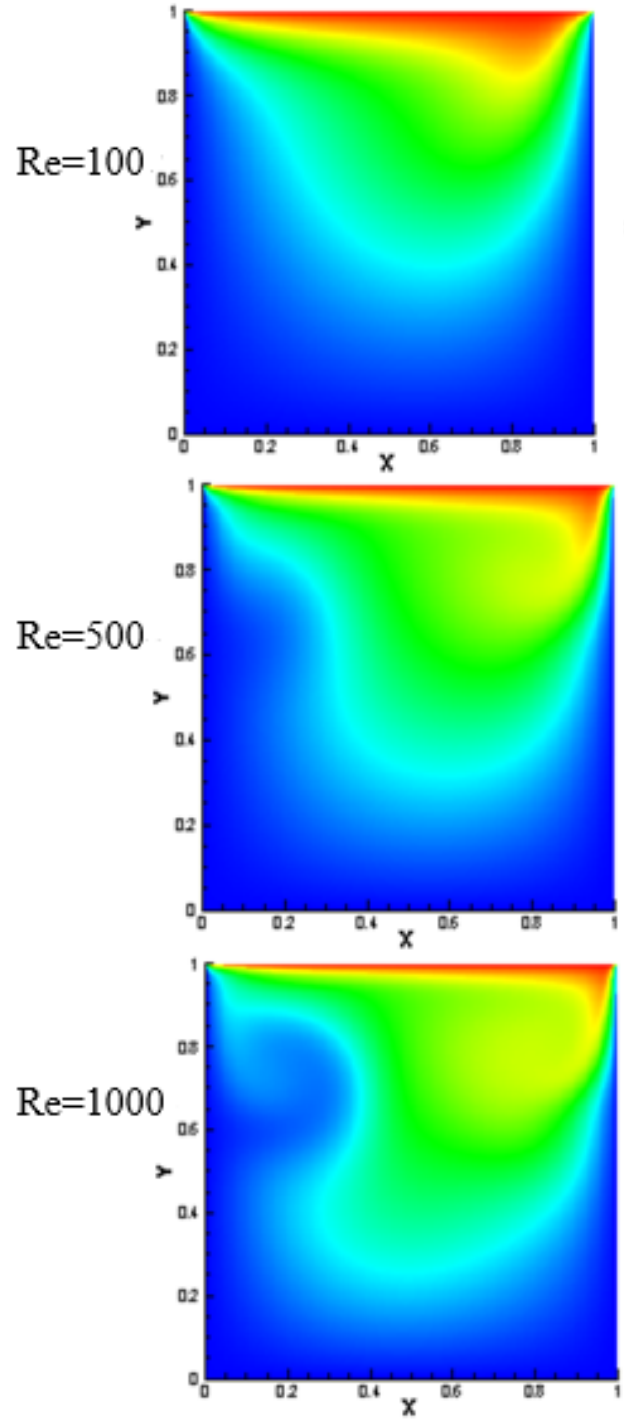

$\mathrm{t}=1.2, \mathrm{U}=0.30901$
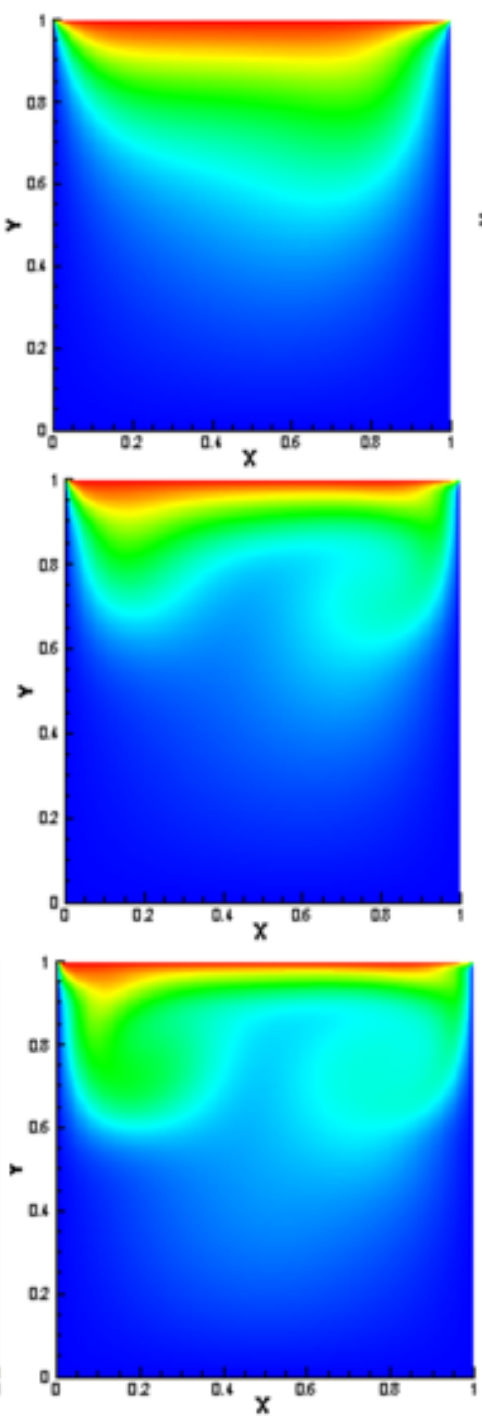

$\mathrm{t}=2.4, \mathrm{U}=-0.80901$
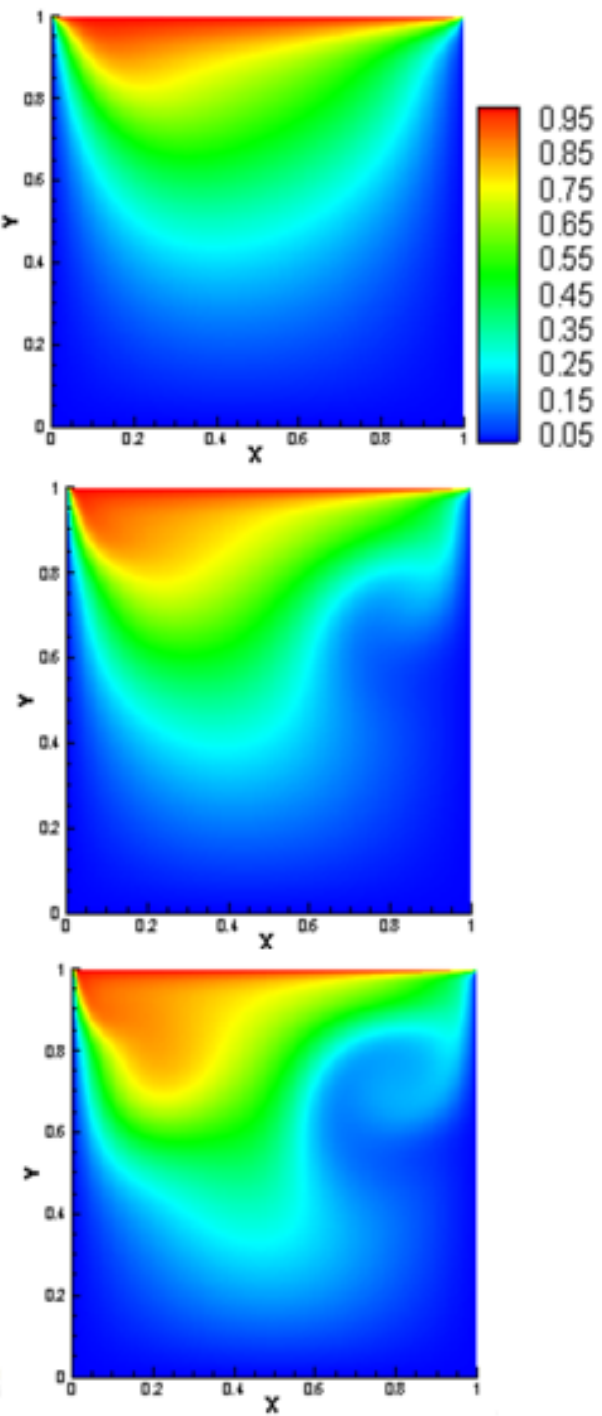

$\mathrm{t}=3.0, \mathrm{U}=-1.0$

Figure 10. Schematic diagrams representing the temperature contours of oscillating lid driven cavity for the heated top wall at first half cycle with $\omega=2 \pi / 6, \operatorname{Pr}=1.0$ for three Reynolds numbers $(\operatorname{Re}=100,500,1000)$

\subsubsection{Nusselt number variation}

Figure 11 displays the time average Nusselt number for various Prandtl number (0.2-1.0) varying with Reynolds number. From figure 11 it is inferred that as the Prandtl number increases, the average Nusselt number variation is increasing and also it is found that at high Reynolds number $(\mathrm{Re}=1000)$ the rate of increase in time average Nusselt number is more when compared to low Reynolds numbers $(\mathrm{Re}=100,500)$. This behaviour is basically due to the dominance of molecular diffusion of momentum.

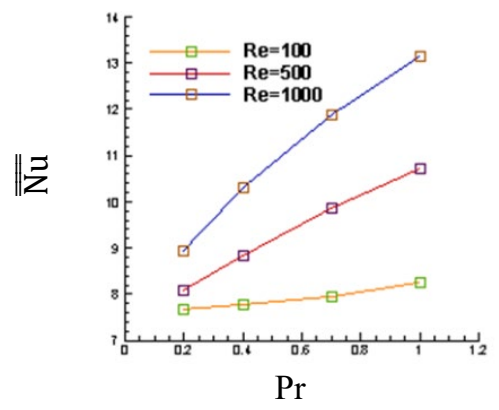

Figure 11. Schematic diagram representing the time average Nusselt number variation with Prandtl number

\section{CONCLUSIONS}

In this paper, we develop a two-dimensional numerical model to examine the flow patterns in a square cavity with oscillating lid (oscillating upper wall, oscillating parallel wall sync oscillating anti-parallel wall reverse sync) and also the heat transfer characteristics in a cavity with an oscillating upper wall having a hot upper lid. The present computational model is developed with finite volume method using a staggered grid arrangement. Initially, the developed numerical model is validated by comparing our simulation results with that of other researcher's results. Then, several numerical experiments are done for the cases of oscillating lid driven cavity with best-operating parameters for mixing i.e. at Reynolds number $(\operatorname{Re}=100,500,1000,2000)$ and optimum frequency $\omega=\frac{2 \pi}{6}$. It is observed from the vorticity plots that the disturbance of fluid mass is more in case of anti-parallel wall when compared to the other two cases. Finally, the heat transfer characteristics are studied for a cavity with oscillating lid (oscillating upper wall) having top wall heated at different Prandtl numbers $(\operatorname{Pr}=0.7,1.0)$ and Reynolds numbers $(\mathrm{Re}=100,500,1000)$. From the isotherms, 
it is observed that for high Prandtl number case $(\operatorname{Pr}=1.0)$ the heat transfer distribution inside the cavity is more when compared with low Prandtl number cases due to increase in molecular diffusion of momentum. At last, it is inferred that as Prandtl number increases, the time average Nusselt number variation is increasing. It is found that at high Reynolds number $(\mathrm{Re}=1000)$ the rate of increase in time average Nusselt number is more when compared to low Reynolds numbers $(\mathrm{Re}=100,500)$. Finally, it is determined that oscillating anti-parallel wall with reverse sync gives better mixing of the fluid inside the cavity at $\mathrm{Re}=1000$. It is also seen that better heat transfer characteristics are observed at high Prandtl number and Reynolds number cases

\section{ACKNOWLEDGEMENT}

This work was supported by National Institute of Technology Karnataka (NITK), Surathkal, India.

\section{REFERENCES}

[1] Hasnat M, Kaid N, Bensafi M, Belkacem. (2015). A numerical technique finite volume method for solving diffusion 2D problem. The International Journal of Engineering and Science 4(10): 35-41.

[2] Pan F, Acrivos A. (1967). Steady flows in rectangular cavities. Journal of Fluid Mechanics 28(04): 643-655. https://doi.org/10.1017/S002211206700237X

[3] Koseff JR, Street RL. (1984). On end wall effects in a lid-driven cavity flow. Journal of Fluids Engineering 106(4): 385-389. http://dx.doi.org/10.1115/1.3243135

[4] Street RL. (1984). Visualization studies of a shear driven three-dimensional recirculating flow. Journal of Fluids Engineering 106: 21. http://dx.doi.org/10.1115/1.3242393

[5] Prasad AK, Koseff JR. (1989). Reynolds number and end-wall effects on a lid-driven cavity flow. Physics of Fluids A, Fluid Dynamics 1(2): 208-218. https://doi.org/10.1063/1.857491

[6] Ghia UKNG, Ghia KN, Shin CT. (1982). High-Re solutions for incompressible flow using the NavierStokes equations and a multigrid method. Journal of Computational Physics 48(3): 387-411. https://doi.org/10.1016/0021-9991(82)90058-4

[7] Patil DV, Lakshmisha KN, Rogg B. (2006). Lattice Boltzmann simulation of lid-driven flow in deep cavities. Computers \& Fluids 35: 1116-1125. https://doi.org/10.1016/j.compfluid.2005.06.006

[8] Perumal DA, Dass AK. (2011). Multiplicity of steady solutions in two-dimensional lid-driven cavity flows by lattice boltzmann method. Computers \& Mathematics with Applications 61(12): 3711-3721. https://doi.org/10.1016/j.camwa.2010.03.053

[9] Bruneau CH, Saad M. (2006). The 2D lid-driven cavity problem revisited. Computers \& Fluids 35(3): 326-348. https://doi.org/10.1016/j.compfluid.2004.12.004

[10] Lin LS, Chen YC, Lin CA. (2011). Multi relaxation time lattice Boltzmann simulations of deep lid driven cavity flows at different aspect ratios. Computers \& Fluids 45(1): 233-240. https://doi.org/10.1016/j.compfluid.2010.12.012

[11] Lin LS, Chang HW, Lin CA. (2013). Multi relaxation time lattice Boltzmann simulations of transition in deep 2D lid driven cavity using GPU. Computers \& Fluids 80 381-387.

https://doi.org/10.1016/j.compfluid.2012.01.018

[12] Pandit SK, Kalita JC, Dalal DC. (2007). A transient higher order compact scheme for incompressible viscous flows on geometries beyond rectangular. Journal of Computational Physics 225(1): 1100-1124. https://doi.org/10.1016/j.jcp.2007.01.016

[13] Aydm O. (1999). Aiding and opposing mechanisms of mixed convection in a shear-and buoyancy-driven cavity. International Communications in Heat and Mass Transfer 26(7): 1019-1028. https://doi.org/10.1016/S0735-1933(99)00091-3

[14] Burgos J, Cuesta I, Salueña C. (2016). Numerical study of laminar mixed convection in a square open cavity. International Journal of Heat and Mass Transfer 99: 599-612.

https://doi.org/10.1016/j.ijheatmasstransfer.2016.04.010

[15] Abdelmassih G, Vernet A, Pallares J. (2012). Numerical simulation of incompressible laminar flow in a threedimensional channel with a cubical open cavity with a bottom wall heated. In Journal of Physics: Conference Series 395(1): 012099. https://doi.org/10.1088/17426596/395/1/012099

[16] Khanafer KM, Al-Amiri AM, Pop I. (2007). Numerical simulation of unsteady mixed convection in a driven cavity using an externally excited sliding lid. European Journal of Mechanics-B/Fluids 26(5): 669-687. https://doi.org/10.1016/j.euromechflu.2006.06.006

[17] Iwatsu R, Hyun JM, Kuwahara K. (1993). Numerical simulations of three-dimensional flows in a cubic cavity with an oscillating lid. Journal of Fluids Engineering 115(4): 680-686. http://dx.doi.org/10.1115/1.2910199

[18] Sriram S, Deshpande AP, Pushpavanam S. (2006). Analysis of spatiotemporal variations and flow structures in a periodically driven cavity. Journal of Fluids $\quad$ Engineering 128(3): 413-420. http://dx.doi.org/10.1115/1.2173289

[19] Mendu SS, Das PK. (2013). Fluid flow in a cavity driven by an oscillating lid-A simulation by lattice Boltzmann method. European Journal of MechanicsB/Fluids 39 : 59-70. https://doi.org/10.1016/j.euromechflu.2012.12.002

[20] Hu Z, Zheng X, Ma QW, Duan WY. (2015). Fluid flow in a cavity driven by an oscillating lid by an improved incompressible SPH. Procedia Engineering 126: 275279. https://doi.org/10.1016/j.proeng.2015.11.241

[21] Saeidi SM, Khodadadi JM. (2006). Forced convection in a square cavity with inlet and outlet ports. International Journal of Heat and Mass Transfer 49(11): 1896-1906.

https://doi.org/10.1016/j.ijheatmasstransfer.2005.10.033

[22] Dos Santos ED, Petry AP, Rocha LA, França FH. (2013). Numerical study of forced convection lid-driven cavity flows using LES (Large Eddy Simulation). Journal of Energy and Power Engineering 7(9): 1669.

[23] Varma IJ, Maniyeri R. (2017). Numerical simulation of oscillating lid driven cavity. Alexandria Engineering Journal, Article in Press. https://doi.org/10.1016/j.aej.2017.07.011

[24] Patankar S. (1980). Numerical heat transfer and fluiflow. CRC Press. http://dx.doi.org/10.1201/9781482234213 